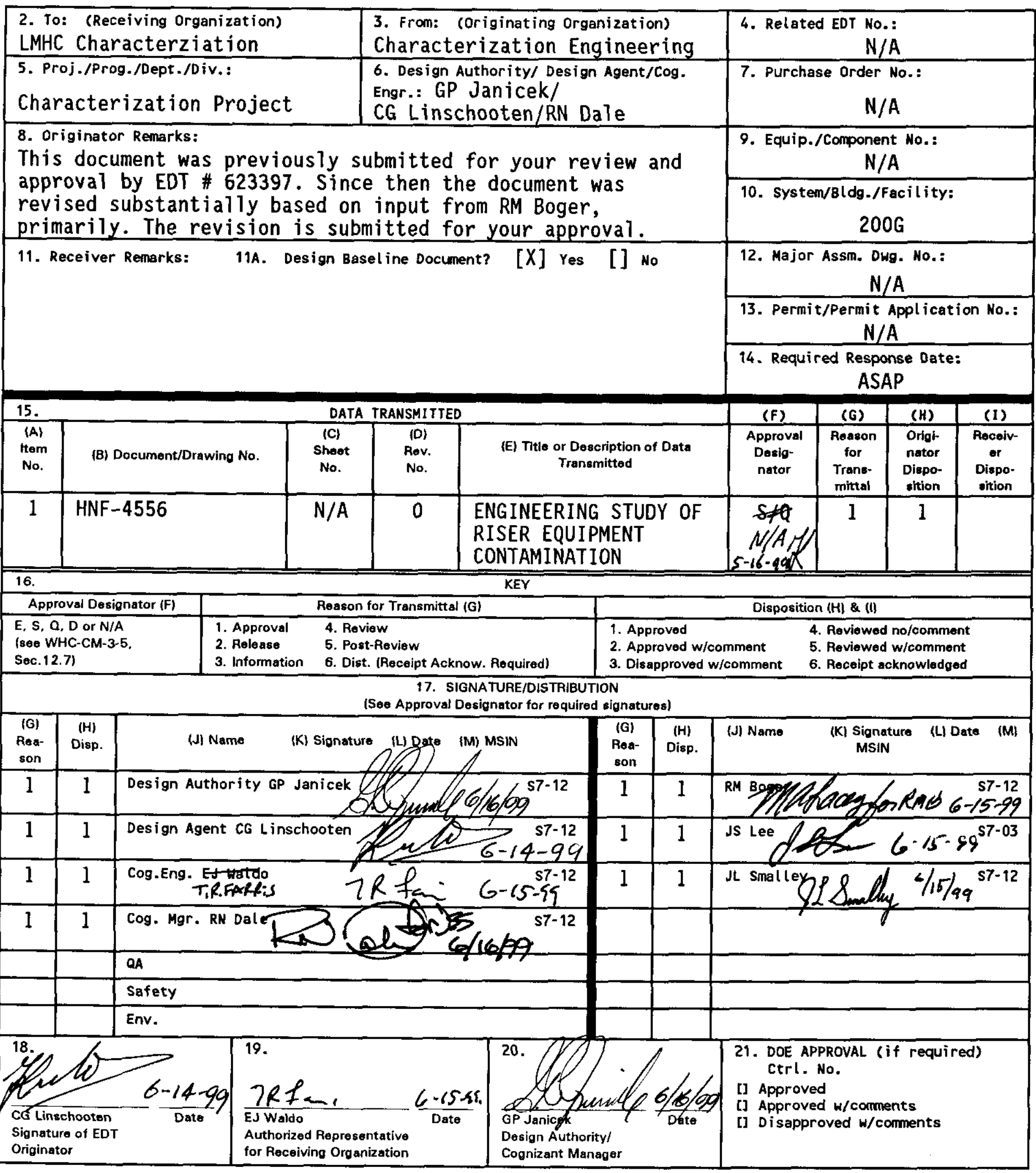

BD-7400-172-2 (05/96) GEF097 


\section{$s$ \\ ENGINEERING STUDY OF RISER EQUIPMENT CONTAMINATION}

HNF-4556, Rev. 0

R.M. Boger

Prepared by Lockheed Martin Hanford Company

Richland, WA 99352

U.S. Department of Energy Contract DE-AC06-96RL13200

EDT/ECN: 623404

UC: 2070

Org Code: 74900

Charge Code: 102250

B\&R Code: EW 3120074

Total Pages: 14

Key Words: Characterization Project; Engineering Study; Sampling; Riser; Riser Equipment; Decontamination.

Abstract: This Engineering Study was to evaluate the current equipment and operating procedures to determine if changes could be made to improve ALARA and evaluate the feasibility of implementing the proposed solutions. As part of this study input from the cognizant characterization engineers and operating sampling crews was obtained and evaluated for ALARA improvements.

TRADEMARK DISCLAIMER. Reference herein to any specific commercial product, process, or service by trade name, trademark, manufacturer, or otherwise, does not necessarily constitute or imply its endorsement, recommendation, or favoring by the United States Government or any agency thereof or its contractors or subcontractors.

Printed in the United States of America. To obtain copies of this document, contact: Document Control Services,

P.O. Box 950, Mailstop H6-08, Richland WA 99352, Phone (509) 372-2420; Fax (509) 376-4989.
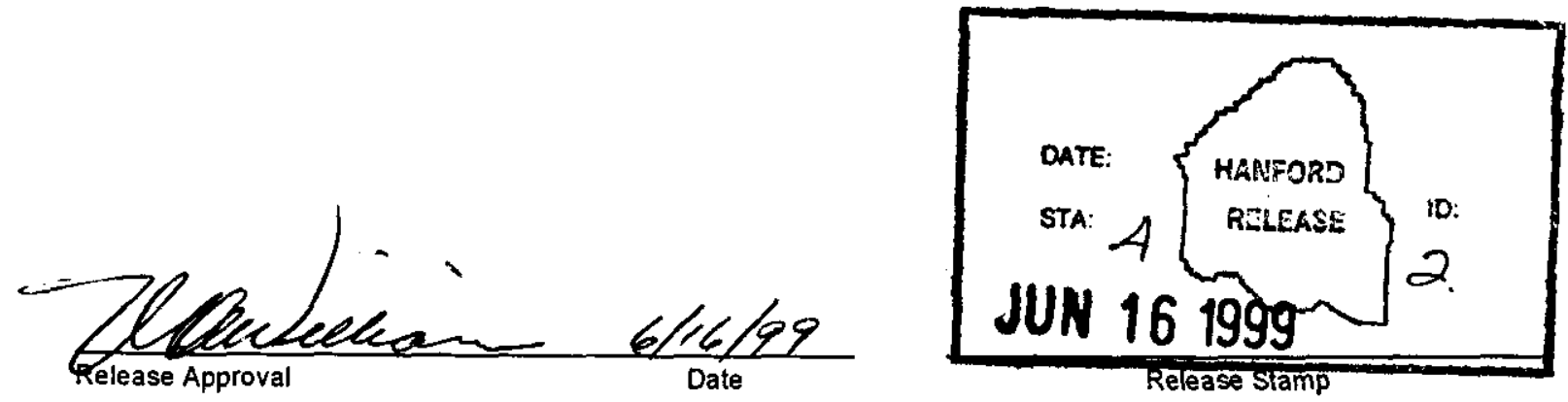

\section{Approved For Public Release}


HNF-4556, Rev. 0

\section{ENGINEERING STUDY OF RISER EQUIPMENT CONTAMINATION.}

Prepared for Lockheed Martin Hanford Corporation

Characterization Engineering Group

By

C.G. Linschooten

Numatec Hanford Corporation

May 1999 
TABLE OF CONTENTS

1.0 INTRODUCTION

1.1 BACKGROUND

1.2 SCOPE

2.0 SUMMARY

3.0 EQUIPMENT DESCRIPTION

4.0 DESCRIPTION OF ALTERNATIVES AND SOLUTION

5.0 UNCERTAINTIES

6.0 CONCLUSIONS

7.0 REFERENCES

APPENDIX A: Linschooten, CG 1999a, MEETING MINUTES, TWRS/CHARACTERIZATION ENGINEERING, RISER EQUIPMENT DECONTAMINATION, date: 2-15-99 A1-A2

APPENDIX B: Linschooten, CG 1999b, MEETING MINUTES, TWRS/CHARACTERIZATION ENGINEERING, RISER EQUIPMENT DECONTAMINATION, date: $4-12-99$

TABLE OF FIGURES

Figure 1: NEW WASHER ASSEMBLY

Figure 2: DRILL ROD WASHER ASSY WITH STRAINER

Figure 3: PUMP ASSEMBLY WITH 5 TO 6 GALLON DRUM

Figure 4: SERVICE PANEL SCHEMATIC WITH OVERRIDE

Figure 5: COSTS STRAINER, DRUM FOR FLUSHING \& 


\subsection{INTRODUCTION}

\subsection{BACKGROUND}

On October 15, 1998, two Characterization Project Operations employees were found to have contaminated clothing. Details of this occurrence can be found in PC ORPS Occurrence Report RL-PHMC-TANKFARM-1998-0128 [LMHC 1988a]. Corrective action number 07 of this report asked Engineering to examine the process methodology used for core sampling operations to determine practicality and potential long-term advantages of reducing personnel contact with contaminated equipment. To accomplish this task an Engineering Task Plan HNF-3700 was written and released 2-9-99.

\subsection{SCOPE}

The scope of this engineering study was to evaluate the current equipment and operating procedures to determine if changes could be made to improve ALARA and evaluate the feasibility of implementing the proposed solutions. As part of this study input from the cognizant characterization engineers and operations sampling crews was obtained and evaluated for ALARA improvements.

\subsection{SUMMARY}

The study reviewed the existing design and operating procedures and determined that:

For a near term solution:

- Sampling Operations needs to use all the available equipment during operation in order to reduce the potential spread of contamination. The washing system should always be used before retrieving parts out of the riser, instead of leaving it up to the Person In Charge (PIC)'s discretion as is now allowed by the operating procedure.

- The design improvement per work packages ES-97-0079 and ES-97-0080 to modify the washing pump on two support trucks needs to be incorporated as soon as possible. This modification was not in service at the time of the contamination event and may have reduced the severity or precluded the event if it had been used.

- The reliability improvements identified in section 4 needs to be implemented. Specifically a filter in front of the washers, an interlock to lock out the drum heater and pump out the heel in the drum, and a 5-gallon flush of clean water at the end of the spray washing cycle to prevent corrosion due to the use of Lithium Bromide (Libr).

For a long term solution:

- New Riser Equipment designed from the ground up with ALARA in mind, to reduce potential contamination spread, needs to be implemented. 


\subsection{EQUIPMENT DESCRIPTION}

The different configurations of the riser assembly are depicted in the Drill String arrangement drawing H-2-690134. View " $A$ " on sheet 1 of this drawing gives a typical situation. The details of this arrangement are:

The Drill Rod Washer Manifold Assembly and Details are shown on drawing H-2-91671 sheet 1 thru 3,

The Riser Adapter Assembly drawing H-2-690132 sheet 1, The Riser Sleeve assembly H-2-690128 sheet 1 \& 2,

The Riser Sleeve Spray Washer drawing H-2-690131 sheet 1 \& 2.

For the set-up-, teardown- and operating procedures see:

- TO-020-451 Set-up and Take Down Core Sample Systems.

- TO-080-518 Tank Farm Plant Operating Procedure, Core Sampling with Truck 3 and 4 (Rotary Bit).

- TO-080-519 Tank Farm Plant Operating Procedure, Core Sampling with Truck 3 and 4 (Push Bit).

\subsection{DESCRIPTION OF ALTERNATIVES AND SOLUTIONS.}

In addition to reviewing the equipment and procedures in section 3, meetings were held to gain a better understanding of the design and operation of the equipment. The minutes for these meetings are shown in Appendix A and B.

The following alternatives were generated as a result of this activity:

1) Do Nothing:

- Continue to operate in the current manner with the existing equipment. This alternative does not reduce the potential contamination to the operator but maintains status quo.

2) Utilize all existing equipment:

- Use all the available equipment and the operation to be considered as a worst case scenario. The washing system should always be used before retrieving parts out of the riser, instead of leaving it up to the PIC's discretion as is now allowed by the operating procedure. This alternative would reduce the spread of contamination to the riser equipment, therefore reducing the potential risk of contamination to the operators.

- As part of this alternative the new spray wash design would be incorporated. This design improvement, which has already been planned (work packages ES-97-0079 and ES-97-0080), was not in service at the time of the contamination event and may have reduced the severity or precluded the event if it had been used.

3) New Riser Equipment Design should be done with the guidance of ALARA, which will reduce the potential of radiation exposure to the operator and will reduce the potential risk of contamination spread. 
The following parameters should be considered:

- A design evaluation should be done along the lines of ALARA.

- The equipment should be designed void of any nooks and crannies on the inside as well as the outside.

- The orientation of the parts with chamfers and skirts for water flow should be chosen carefully to by-pass seams and make dripping easier to a lower level.

- Tapers, smooth surfaces and smooth transitions should be used to increase the ease of the liquid flow and prevent accumulation and adherence of contamination as much as possible.

- The design should have the least amount of seams.

- Perhaps more or different kind of washers could be used with increased water pressure; more water or even warm water.

- Develop cleaning wands .

- Simplify the design for the washing stations.

- The Pipe Wiper H-2-690134 P/N 41, which cleans the drill string, could be redesigned.

A design effort can be made to simplify the equipment by:

- Getting rid of all the loose parts, making it more of a one-part installation.

- Try to come up with a "One Design" fits all, in other words standardization and simplification of equipment. See figure 1.

- A new footclamp could be used which is easier to clean and is less prone to hold contamination.

4) Design an equipment decon unit:

- An ultra sonic cleaning station or a $\mathrm{CO} 2$ decon facility for sampling equipment and other equipment used in the tankfarms could be developed for decon of the Grapple, RLU, Change Out Assembly, Cable spray Washer, Pipe Wiper etc.. This alternative would reduce the long term build up of contamination to the tank equipment, as well as support equipment. The results of this would reduce the potential of exposure to the operators.

5) Reliability Improvements:

Clogging up of the spray nozzles of the current spray washers occurs during normal operation. When this clogging of the spray wash nozzles occurs, the nozzles have to be taken out, cleaned and re-installed. This kind of maintenance in the field increases the exposure of the operators and increases the spread of potential contamination. A strainer installed right in front of the washers would greatly reduce or prevent the clogging and reduces the potential of exposure and contamination to the operators. See figure 2. (This picture comes from Dwg. H-2-91671 sht. 1).

The Lithium Bromide ( $\mathrm{LiBr}$ ) is suspected of causing corrosion in the spray wash system, which makes loose particles float in the washing stream and clog up the spray nozzles. 
It is believed that even the rubber hose deteriorates in high concentrations of $\mathrm{LiBr}$. The following steps should be taken to minimize corrosion caused by the use of $\mathrm{LiBr}$ :

- Parts and vendor search could be done to find a better hose.

- Minimize the corrosion by using a 5-gallon vessel with clean water and flush the system at the end of the washing cycle. See figure 3. (This picture comes from Dwg. H-2-81853 sht. 5).

- Investigate replacement of the $\mathrm{LiBr}$ solution with another liquid with a tracer, which is less corrosive and less detrimental to the pump and the washing system.

- Investigate replacement of other spray wash components, which may be susceptible to corrosion of $\mathrm{LiBr}$. Originally the system was designed for water with a maximum temperature of approx. 135 degrees $F$.

The results of this activity would reduce equipment downtime, which would increase its potential use.

A suggestion was made by one of the Cognizant Engineers to override the low liquid level pump stop, which prevents the heater from burning out, in order to pump out the rest of the liquid in the 55-gallon drum. The override would only work if the heater were turned off. See figure 4. (This picture comes from dwg. H-2-81853 sht.6). The reason being that the possible higher concentration of the $\mathrm{LiBr}$ increases the corrosion of the equipment. In addition the sediment in the bottom of the 55-gallon drum with its possible higher concentration of $\mathrm{LiBr}$ will cause inaccuracies in the laboratory analysis. Right now a sample is sent to the lab of the $\mathrm{LiBr}$ water mixture before it is deposited into the 55gallon drum.

\subsection{UNCERTAINTIES}

No significant uncertainties were found in the development of this document.

\subsection{CONCLUSIONS}

The study review of the use of the existing riser equipment concluded, that every time sampling is done, all the available equipment should be used and the operation to be considered as a worst case scenario. The washing system should always be used before retrieving parts out of the riser. Currently, the operating procedure leaves it up to the PIC's discretion as to whether or not to use part of the spray wash equipment. If this practice is done consistently the contamination should be kept in bounds, without changing the current design.

The design improvement per work packages ES-97-0079 and ES-97-0080 to increase the washing pump capacity and the pump pressure will give improved washing performance. This work should be finished as soon as possible.

Review of the existing riser equipment concluded that there are a lot of nooks and crannies were the contamination can take hold. The long-term solution will be to design a Drill Rod Washer Manifold and subsequent assemblies with all smooth transitions and 
optimum ALARA consideration in mind. In other words design all the nooks and crannies out of the assembly. In the meantime simplify the overall design, minimize the amount of assemblies and make those assemblies fit all or most situations. See fig. 1. The cost for such Riser Equipment is estimated at \$80,000, which includes design, engineering, materials, fabrication and testing.

Reliability improvements to increase the performance of the current equipment should be instituted. These improvements are:

- Installing a strainer in front of the washer to prevent clogging up of the spray wash nozzles in the washers.

- And prevent corrosion due to the use of LiBr by flushing the Drill Rod Manifold Assembly with 5 to 6 gallons of clean water at the end of the spray washing cycle.

- To prevent an accidental increase in $\mathrm{LiBr}$ concentration in the 55-gallon drum it is advisable to pump out the heel in the 55-gallon drum. In order to do this pumping, an override is necessary to override the low level liquid pump stop and turn off the heater at the same time.

For the cost of the strainer, the 5-gallon flush drum and the override for the low liquid level pump stop see fig 5 .

NOTE: The figures one through four are to be viewed as potential future concepts, not as a final design solution

\subsection{REFERENCES}

LMHC 1998a, Occurrence Report, RL-PHMC-TANKFARM-1998-128, Lockheed Martin Hanford Company, Richland, Washington.

LMHC 1999a, HNF-3700 RISER EQUIPMENT DECONTAMINATION ENGINEERING TASK PLAN. Lockheed Martin Hanford Company, Richland, Washington.

LMHC 1999b, TANK FARM PLANT OPERATING PROCEDURE, TO-080-518, CORE SAMPLING WITH TRUCK 3 AND 4 (ROTARY BIT). Lockheed Martin Hanford Company, Richland, Washington.

LMCH 1998b, TANK FARM PLANT OPERATING PROCEDURE, TO-080-519, CORE SAMPLING WITH TRUCK 3 AND 4 (PUSH BIT). Lockheed Martin Hanford Company, Richland, Washington.

LMHC 1999c, SET-UP AND TAKE DOWN CORE SAMPLE SYSTEM, TO-020-451. Lockheed Martin Hanford Company, Richland, Washington. 
HNF-4556, Rev. 0

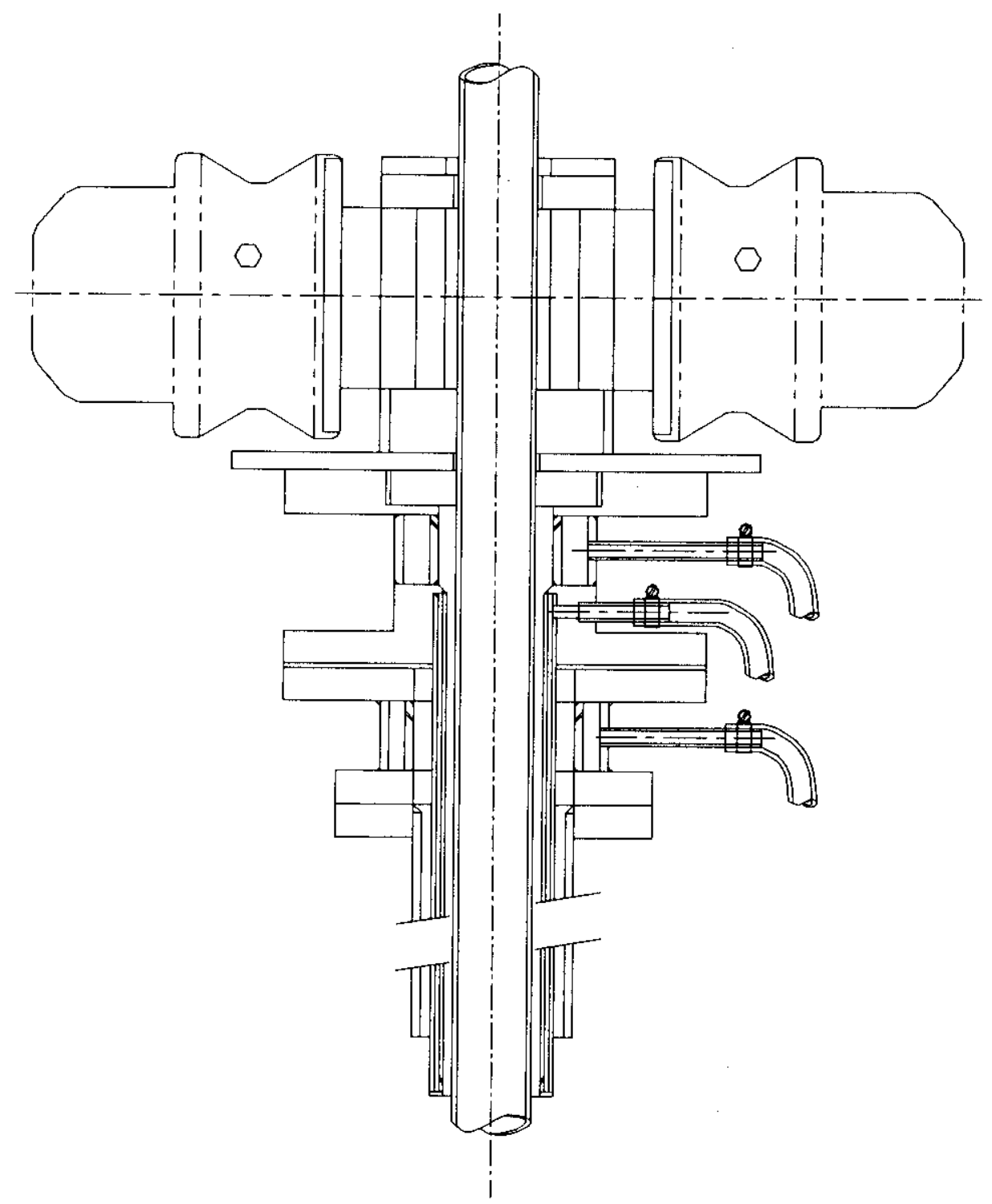

FIGURE 1, NEW WASHER ASSEMBLY 


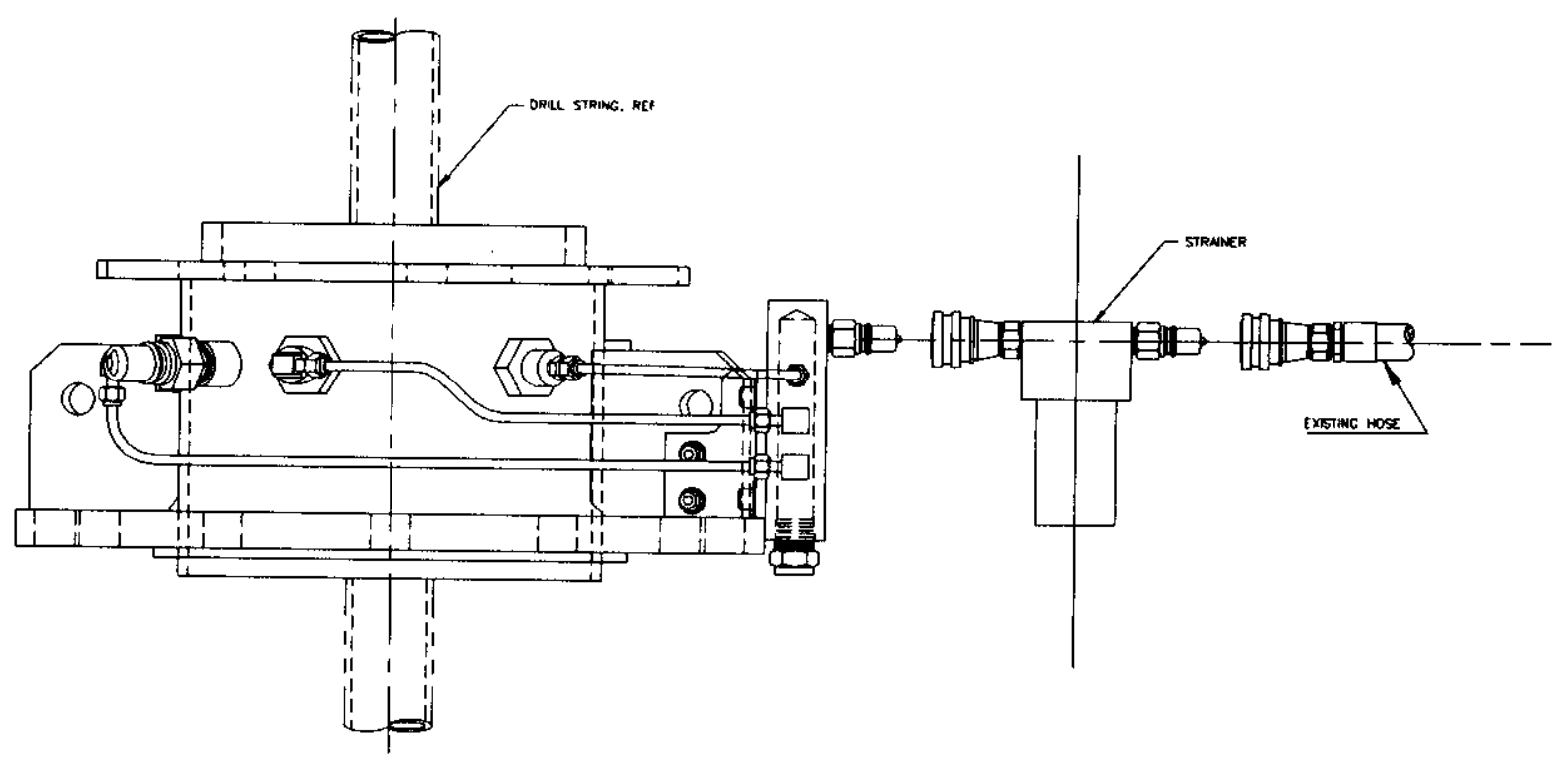

FIGURE 2, DRILL ROD WASHER ASSY WITH STRAINER (fils::0osiasso)

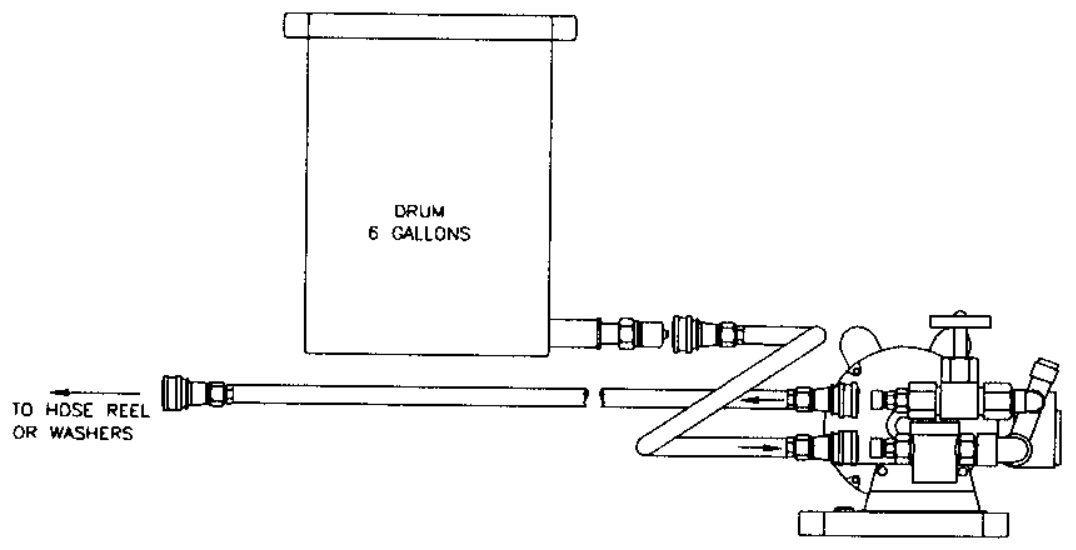

FIGURE 3. PUMP ASSY WITH 5 TO 6 GALLON DRUM 


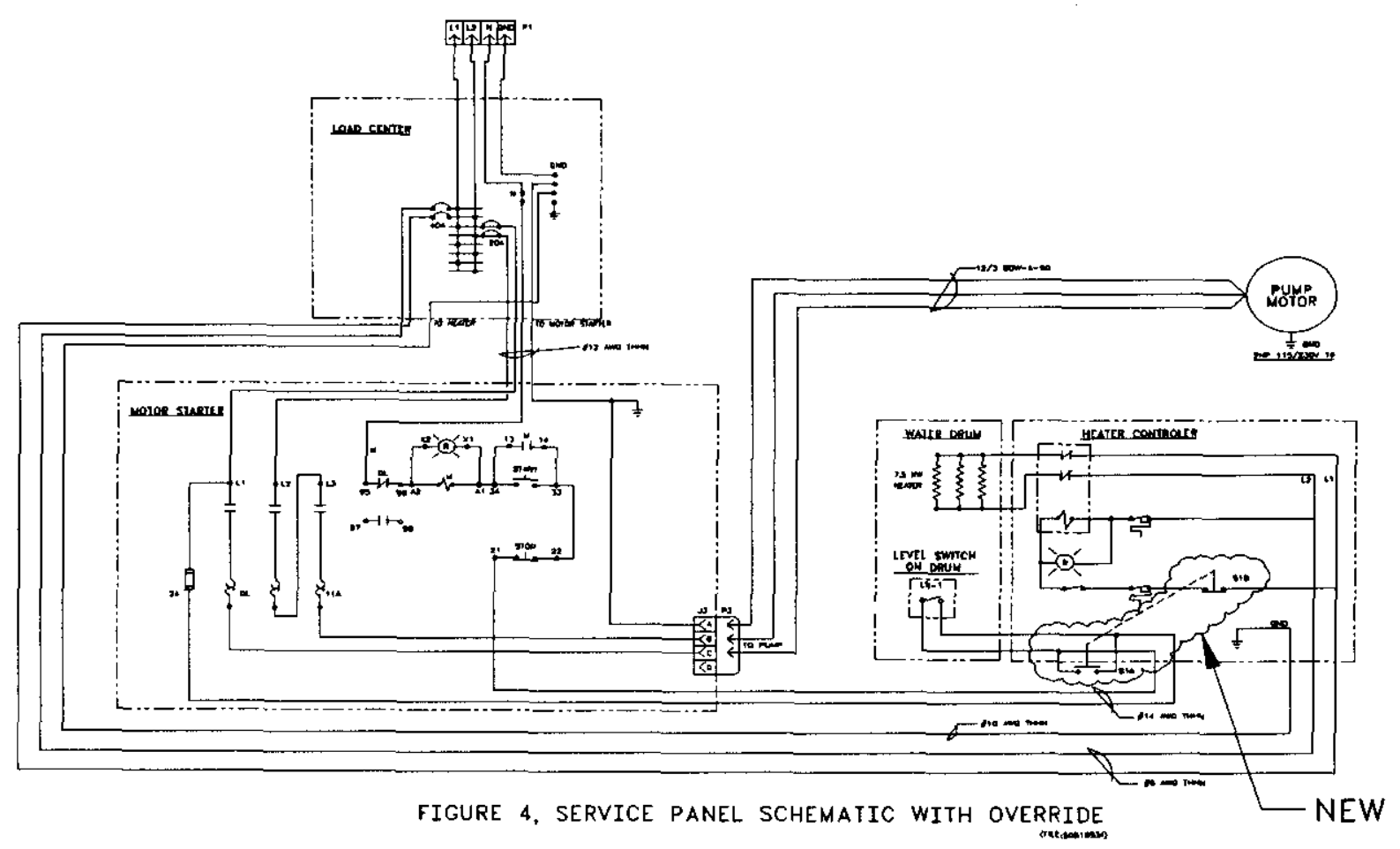

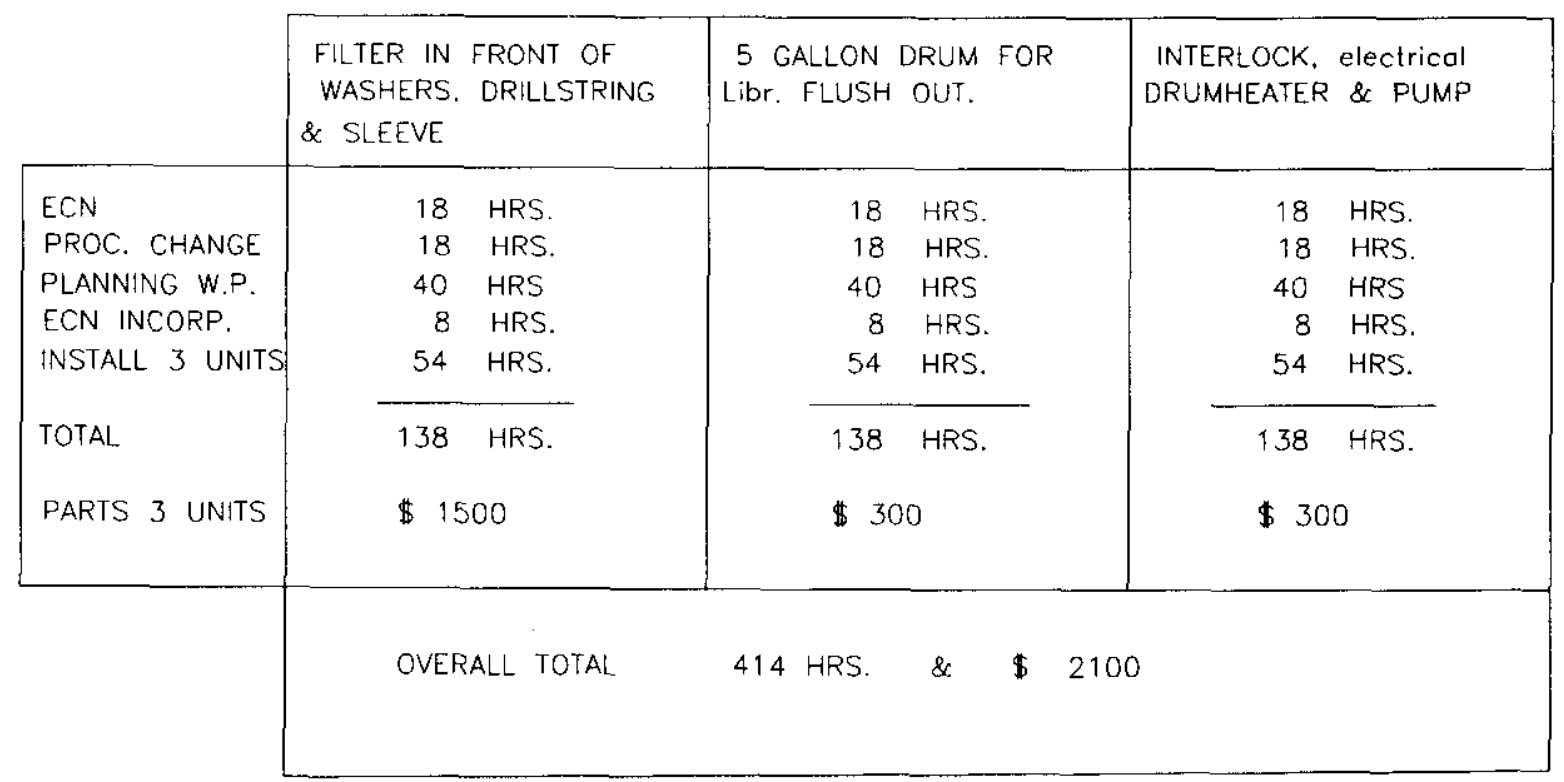

FIGURE 5

BEST AVAILABLE COPY 


\section{MEETING MINUTES}

SUBJECT: Riser Equipment Decontamination

TO:
Distribution

FROM:

C. G. Linschooten

DEPARTMENT-OPERATION-COMPONENT

TWRS/Characterization Engineering

\section{Decontamination}

\section{CC: Attendees}

$\begin{array}{ll}\text { R. M. Boger } & 57-12 \\ \text { J. S. Lee } & 57-03\end{array}$

Attendees:
Brad Coverdell
$57-12$
S7-03
Ted Jarecki
S7-12
Chris Linschooten
Jeff Smalley
Galen Wilson
S7-12
S 7-12
Al Kostelnik
S 7-12

S7-12

On October 15, 1998, two Characterization Project Operations employees were found to have contaminated clothing. (See PC ORPS Occurrence Report RL - - PHMC-TANKEARM-1998-0128.)

Corrective action number 07 of this report requested that characterization Engineering examine the process methodology used for core sampling operations to determine practicality and potential long-term advantages of reducing personnel contact with contaminated equipment.

To accomplish this task an Engineering Task Plan, HNF-3700, was written, and was released February 9, 1999.

The following recommendations were made:

A design evaluation should be done along the lines of ALARA. The design should be as much as practical void of any nooks and crannies on the inside as well as the outside. A new footclamp could be used which is easier to clean and is less prone to hold contamination. Orientation of the parts with chamfers and skirts for water flow to by-pass seams or make dripping easier to a lower level. Tapers, smooth surfaces, and smooth transitions can be used. The design should have the fewest number of seams. perhaps more or a different kind of washers could be used with increased water pressure, more water or even warm water and perhaps develop cleaning wands. Simplify the design for washing stations. 
A design effort can be made to simplify the equipment by doing the following:

Get rid of ali the loose parts, making it more of a one-part installation. And try to come up with a "One Design fits All" (i.e., standardization and simplification of equipment).

The cleaning frisbee, which cleans the drill string, might be redesigned, perhaps using a different material.

It might help that every time sampling is done all the available equipment is used and the operation is considered a worst_case scenario.

Another recommendation was that an Equipment Decon Unit should be considered le.g., an ultra-sonic cleaning station or a co2 decon facility for sampling equipment and other equipment used in the tank farms such as the Grapple and the RIU, etc).

Only 40 more core samples are to be taken in the future. For economic reasons it might be better to leave the equipment as is and use extra caution when operating. 


\section{MEETING MINUTES}

SUBJECT: Riser Equipment Decontamination

\begin{tabular}{|c|c|c|c|c|}
\hline $\begin{array}{l}\text { TO: } \\
\text { Distribution }\end{array}$ & & $\begin{array}{l}\text { BUILD } \\
270\end{array}$ & 38 & \\
\hline $\begin{array}{l}\text { FROM: } \\
\text { Characterization Engineering }\end{array}$ & & CHAIF & ischooten & 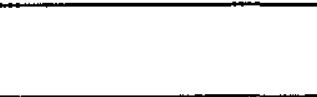 \\
\hline DEPARTMENT-OPERATION-COMPONENT & $\begin{array}{l}\text { AREA } \\
200 E \\
\end{array}$ & $\begin{array}{l}\text { SHIFT } \\
\text { N/A }\end{array}$ & $\begin{array}{r}\text { DATE OF MEETING } \\
04 / 12 / 99\end{array}$ & $\begin{array}{c}\text { NUMBER ATTENDING } \\
7 \\
\end{array}$ \\
\hline
\end{tabular}

Attendees: Monte Dunnihngton, Brad Ekstrom, Dan Harris, Mike Jones, Bob Parks, Troy Earris, and Chris Linschooten
cc: R. M. Boger
J. S. Lee
J. L. Smalley

Clogging of the spray nozzles of the washers seems to be the main concern, after which the nozzles have to be taken out, cleaned, and re-installed. A filter installed right in front of the washer would be a big help and most likely would prevent the clogging.

The LiBr is blamed for much of the corrosion, which makes loose particles float in the washing stream and clog up the spray nozzles. It is said that even the rubber hose deteriorates. A parts-and-vendor search could be done to find a better hose. To minimize the corrosion it was mentioned to have a 5-gallon vessel with clean water and flush the system at the end of the washing cycle. An alternative would be to replace the LiBr with another liquid with a tracer, which is less corrosive and less detrimental to the pump and the washing system.

Perhaps the whole system should be made out of a material that can handle the LiBr. Originally the system was designed for water with a maximum temperature of approximately 135 degrees $F$.

A suggestion was made to override the low liquid level pump stop, which prevents the heater from burning out, in order to pump out the rest of the liquid in the 55-gallon drum. The overide would only work if the heater were turned off. The reason is that the sediment in the bottom of the 55-galion drum might have a higher concentration of LiBr and so throws off the overall concentration in the laboratory samples. Right now a sample of the mixture is sent to the lab before it is deposited into the 55-gailon drum.

Perhaps the washing system should always be used before retrieving parts out of the riser. Now the operating procedure leaves it up to the PIC's discretion. 